DEBATE

\title{
Grupos en situación de vulnerabilidad y su proyección en el proceso constituyente: Niños, niñas y adolescentes, pueblos indígenas y personas migrantes
}

\section{Introducción}

Los grupos en situación de vulnerabilidad son quienes tienen una posición desventajosa en la sociedad en cuanto al reconocimiento, goce y ejercicio de derechos humanos, como es el caso de los pueblos indígenas; las mujeres; los niños, niñas y adolescentes; las personas mayores; las personas migrantes; las personas con discapacidad y las personas en situación de calle, entre otros.

En el actual proceso constituyente, cabe preguntarse acerca de la existencia de derechos fundamentales específicos en el marco constitucional vigente, sobre las oportunidades y nuevos horizontes que una nueva constitución puede significar para estos grupos, y sobre los mecanismos que aseguren su participación en el proceso constituyente.

Para ello, hemos invitado a tres personas que desde sus roles técnicos o de activismo en la sociedad civil se vinculan con grupos en situación de vulnerabilidad, en específico con pueblos indígenas; niños, niñas y adolescentes; y personas migrantes.

\section{Pregunta 1}

¿Considera usted que el sistema de derechos fundamentales consagrados en la actual Constitución Política y sus garantías permiten asegurar el reconocimiento, goce y ejercicio de tales derechos respecto de los grupos o colectivos sociales que están en condiciones de vulnerabilidad y los que son víctimas de discriminación?

\section{David Órdenes}

La actual Constitución Política ha consagrado el privilegio de los bienes comunes para unos pocos, concentrando de forma absoluta la riqueza y produciendo una gran desigualdad, lo que ha impactado sobre todo en los niños, las juventudes, las mujeres 
y por supuesto en los migrantes como grupos que en particular no han tenido acceso a derechos, lo que se ha agudizado durante la pandemia.

Así, esta estructura, que ha permitido la vulneración de derechos de forma colectiva y sistemática, ha implicado que el sistema como tal no reconozca derechos, limitándose a responder a ciertas necesidades focalizadas que son canalizadas a través de cientos de programas, sin tener como objetivo la lucha contra la desigualdad, sino contener un descontento social.

Lo que se consagró es una forma de relación con la ciudadanía, con las personas, independiente de su situación, desde una perspectiva economicista, capitalista, neoliberal, que al final ha hecho una distribución de la desigualdad, pero no de los derechos garantizados. Por lo tanto, la discriminación es un eje transversal del sistema.

La invitación es a reconocer que no ha habido goce de derechos. Ejemplo de ello es la vulneración a los derechos la niñez bajo custodia del Estado en el Servicio Nacional de Menores, declarada por la Comisión Internacional de los Derechos del Niño, y la mirada en general que existe hacia los niños, a quienes no se les reconoce su participación social y política, sino que se les ha mirado de forma tutelar, como sujetos de protección, pero de ninguna manera como sujetos con participación activa.

En Chile no hay una perspectiva desde el enfoque de derechos, sino una perspectiva de dar respuesta a necesidades muy concretas, que no atienden a las causas del problema.

\section{Héctor Morales}

Debemos considerar que el artículo 1 de la Constitución Política de la República dispone que «las personas nacen libres e iguales en dignidad y derechos. La familia es el núcleo fundamental de la sociedad. El Estado reconoce y ampara a los grupos intermedios a través de los cuales se organiza y estructura la sociedad y les garantiza la adecuada autonomía para cumplir sus propios fines específicos». De la lectura de este artículo podemos responder que no, la Constitución vigente no reconoce en lo absoluto la diversidad cultural de grupos indígenas.

\section{Jhoany Acosta}

La actual Constitución no reconoce al sujeto como persona, no identifica territorios con ese sujeto y no le brinda garantías de derechos. Al no garantizar los derechos, lo que se hace son sólo convenios para superar la pobreza, que no logran conformar una política de Estado.

Si ni siquiera hay garantías de derecho para los sujetos del territorio, mucho menos hay para los migrantes, que no son considerados ni como ciudadanos, ni como trabajadores. La categoría de migrante clasifica y subcategoriza la falta de garantías 
de una población que llega a este país bajo necesidad. Debemos tener presente que la migración chilena es de carácter económica, toda vez que las personas que ingresan al país lo hacen para trabajar y no para estudiar (situación que se da en Argentina, por la gratuidad de la educación).

La migración en Chile tiene distintos componentes. Encontramos muchos sujetos refugiados: el 43,7\% son personas de nacionalidad colombiana que vienen huyendo de sus territorios y deben enfrentar, desde su paso por la frontera, la burocracia para la presentación de solicitudes, mientras que pueden pasar años para que se les reconozca esa calidad. En el tiempo intermedio, van pasando por visas de ocho meses con las que no pueden conseguir trabajo, por lo que su situación es compleja y precaria.

Otra población que ya se volvió histórica es la población dominicana, que ha formado grandes comunidades en distintos lugares, la mayoría de ellos como irregular, pues no están las condiciones para su regularización. La regularización de las personas migrantes siempre ha sido una de las banderas de lucha, porque es sinónimo de dignidad de las personas, de poder tener garantías, de salir a la calle sin miedo, para acceder a los derechos básicos de salud y educación, entre otros.

\section{Pregunta 2}

A su juicio, ¿cuáles son los elementos definitorios a considerar en la configuración del sistema de derechos, en un nuevo orden constitucional, para el reconocimiento y garantía efectiva de los derechos y libertades de los sujetos o grupos sociales que sufren discriminación y que son vulnerados?

\section{David Órdenes}

Creo que un nuevo sistema debe producir un cambio de paradigma mucho más profundo. La nueva constitución debería tener una perspectiva y una mirada desde el enfoque de derechos y abandonar la perspectiva focalizada, que termina siendo vulneradora. Este cambio implica, de alguna manera, un cambio en la red de relaciones de los distintos sistemas que constituyen un Estado, para que sean relaciones de respeto, horizontales, de no discriminación, de igualdad y de oportunidades para acceder a los bienes comunes.

Además de reestablecer la armonía entre las personas, en especial las que han sido más vulneradas, se debe reestablecer una relación con la madre naturaleza para que sea sujeto de derechos, lo que significa no tener sólo una visión o una mirada antropocéntrica, sino también una mirada biocéntrica.

El buen vivir es una forma distinta de convivencia social, de convivencia con la madre naturaleza, que ya están viviendo en distintos países de América Latina. Estas formas de relacionarse con respeto son lo que tenemos que recuperar. Esto va 
acompañado del desafío de lograr que tenga sintonía en los grandes sectores urbanos, donde la relación que tenemos con la naturaleza es un solo árbol y a veces ni siquiera un poquito de pasto, sino sólo una ciudad de cemento.

Otro elemento relevante es el rol del Estado. Considero que lo mínimo que debiera hacer el sistema constitucional es darle una potestad más profunda al Estado, para que recupere el rol que ha sido mermado por condicionantes que provienen de las élites empresariales y políticas, despojándolo de un papel activo y reduciéndolo a proteger las grandes riquezas, al gran empresariado y el extractivismo del sistema planetario.

También es importante considerar que ha habido un cambio en la perspectiva en que los niños, niñas y adolescentes están construyendo un hoy, estableciendo una forma y un mecanismo de diálogo entre ellos y ellas de representación horizontal. En el hoy que están construyendo, plantean una forma distinta de relacionarnos.

Por último, hay que señalar que muchas cosas se deben trabajar. El tema de los pueblos originarios, el respeto a la diversidad de niños, niñas y adolescentes que hay en los pueblos originarios y sus grandes aportes. El tema de los niños y niñas que deben trabajar para tener su existencia. Los migrantes que han llegado a este país y que están haciendo tareas difíciles, a bajo sueldo, hacinados sin que se les haya acogido como personas.

Yo creo que hay un gran trabajo, pero la gran preocupación que tenemos nosotros ahora desde la perspectiva del trabajo que hacemos en los sectores populares es el tema de que haya una alta participación, gente que se la juegue por un buen vivir para todos y para todas, y al final no se concentre esto en personas que estén peleando para mantener el sistema, como es el caso de las tres comunas que votaron por el rechazo.

\section{Héctor Morales}

El reconocimiento constitucional de los grupos indígenas en la constitución impide la visibilidad política de un derecho plurinacional comunitario, libre, independiente, soberano, democrático, intercultural, descentralizado y con autonomías, que se funde en la pluralidad y el pluralismo político, económico, jurídico, cultural y lingüístico, dentro del proceso integrador del país.

\section{Jhoany Acosta}

Sobre la constitución que hoy estamos haciendo, pienso que la Convención Constituyente no es suficiente, pues no nos dará garantías de generar cambios radicales o estructurales en el modelo, dada su preferencia por la participación de partidos políticos. Ello, a pesar de que el movimiento social chileno ha sido muy potente y ha planteado la necesidad de la vinculación a los territorios y a las poblaciones. 
En el caso de la Constitución colombiana, que fue un hito muy importante y bonito en el papel, hubo avances significativos para las poblaciones negra e indígena, que obtuvieron espacios de autonomía muy potentes. A los negros se les reconoció sus palenques, mientras que a los indígenas se les reconoció sus territorios como resguardos indígenas, que son administrados y trabajados de manera autónoma, lo que les permite subsistir, modernizarse, además de ser subsidiados por el Estado de forma permanente en todo su modelo.

Con las condiciones actuales nosotros nada podremos hacer, pero si seguimos avanzando en la organización social y en la participación que hemos ido desarrollando territorialmente, vamos a tener incidencia. Falta que desde la institucionalidad haya una voluntad política. Hace falta regularizar a mucha gente. Muchos no salen porque tienen miedo. No participan de la organización social porque cuando un sujeto pone la firma bajo una solicitud de residencia, debajo de la misma firma te dice que no puede hacer intromisión de asuntos nacionales, en letra pequeña, como una advertencia.

Esa advertencia es constante, si te ven en una marcha te pueden deportar; si te ven en las calles con un libro anarquista, como ha pasado con españoles y peruanos. Ha pasado. Los han sacado por sospecha, porque no les dan confianza, porque consideran que están haciendo intromisión en temas políticos. Entonces la seguridad nacional prima sobre la libertad de expresión, sobre la organización, sobre cualquier espacio para poder participar.

Dado que no hay voluntad política para abrir la participación, es difícil, pero las organizaciones procuramos que la población migrante esté al tanto y sea partícipe. Para el Apruebo, hicimos una campaña que se llamaba «Migrantes por el Apruebo», con enfoque en aquella población con posibilidad de voto y que también ha sido víctima de este modelo, para así poder aportar en este proceso. Me refiero a la población peruana y colombiana, que por lo general llevan más tiempo en el país. La forma territorial es la única por la cual los migrantes podemos ser partícipes en un verdadero proceso constituyente, que sea participativo desde los territorios, desde las organizaciones sociales.

\section{Pregunta 3}

En el caso de grupos sociales que están excluidos de los derechos de ciudadanía -por ejemplo, los niños, niñas y adolescentes, personas indígenas-o ven su ejercicio restringido, como son las personas migrantes, ¿de qué forma consideran que debiera ser garantizada su participación en un proceso constituyente? ¿Cómo debería estructurarse el sistema de derechos en relación con la ciudadanía y el sistema de gobierno para garantizar el reconocimiento y ejercicio de los derechos fundamentales de estos colectivos? 


\section{David Órdenes}

Creo que uno de los elementos fundamentales tiene que ver con garantizar la participación y su carácter de vinculante. Nosotros tenemos una legislación al respecto, la Ley 20.500 sobre Asociaciones y Participación Ciudadana en la Gestión Pública, que generó ciertas directrices al respecto, pero el asunto es que hay una distancia muy profunda entre las leyes y lo que ocurre en la práctica.

Yo creo que en caso de los niños, niñas y adolescentes, un gran llamado tiene que ver con que Chile aún no cuenta con una ley de garantía de derechos de la niñez, habiendo firmado la Convención en 1990.

Chile debe garantizar una participación vinculante que respete, recoja y recree lo que los niños y las niñas están aportando a una nueva sociedad. Pero eso significa además que esa estrategia de participación, esa forma, diríamos, de democracia, debe garantizarse en los territorios desde la base social hasta los contextos globales. Eso implica que acá hay un rol muy importante de que la ley dé garantía de derechos y también, por supuesto, el nuevo orden constitucional garantice la participación desde la base social en los territorios. Estamos hablando desde las poblaciones, desde los pasajes desde las comunas, desde las regiones a lo nacional.

Lo anterior implica el fortalecimiento de la promoción de derechos en participación, de que los niños, niñas y adolescentes tengan la capacidad y la posibilidad de organizarse en representaciones acordes con proyectos propios, de que haya procesos de trabajos con los adultos y de que se ponga fin al adultocentrismo.

Eso implica, de todas maneras, un trabajo profundo, un cambio cultural, una nueva forma de relación. Esa forma de relación pasa por supuesto por que se garantice en el fondo proyectos propios, miradas diversas. Somos un territorio muy amplio a nivel país, con una diversidad de formas de convivencias y formas de vivir, de pueblos originarios también, de diversidad cultural, de esta llegada de inmigrantes de distintos países; por lo tanto, tenemos una riqueza enorme para poder recrear formas de convivencia que sean congruentes con los derechos que realmente todos merecemos.

Requerimos un gran trabajo de educación y de formación para estos cambios profundos, que garanticen una nueva forma de relación y una redistribución del poder, en que nos relacionamos sobre la base del respeto horizontal que nos permita co-construir de forma intergeneracional y transdisciplinaria una sociedad en verdad digna, en la que, como se dice, la dignidad se haga costumbre.

\section{Héctor Morales}

El sistema de derechos en relación con la ciudadanía y sistema de gobierno debería estructurarse reconociendo que, dada la existencia precolonial de las naciones y pueblos indígenas originarios y su dominio ancestral sobre sus territorios, se garantice su 
libre determinación en el marco de la unidad del Estado, que consiste en su derecho a la autonomía, al autogobierno, a su cultura, al reconocimiento de sus instituciones y a la consolidación de sus entidades territoriales, según esta Constitución y la ley.

\section{Jhoany Acosta}

En el caso de las personas migrantes, no tenemos garantizada nuestra participación en el proceso constituyente, ya que no podemos participar en partidos políticos por considerarse una forma de interferir en temas de interés nacional, lo que podría arriesgarnos a ser expulsados del país. Como migrantes, tenemos limitadas nuestras posibilidades de participar, pero sentimos el impulso de querer participar. Tenemos dos candidatos: una persona que lleva mucho tiempo viviendo aquí y otra persona que por nacimiento accede a la nacionalidad chilena, pero ambos son casos particulares.

Del mismo modo que las personas migrantes no tenemos ninguna garantía de poder participar, otros movimientos en Chile se encuentran en una situación similar, como el movimiento ambiental, animalista y feminista.

Si dejamos que la Convención se forme como hoy está planteada, no va a haber ningún proceso estructural para generar garantía de derechos. Hay otros procesos constituyentes, como el ecuatoriano y boliviano, en que se vincularon territorialmente las necesidades. La organización territorial que va a necesitar Arica va a ser muy distinta a la de Santiago o la de Puerto Montt. Ojalá se genere una comisión constituyente para avanzar en cómo la gente quiere que avance el proceso, y no simplemente quedar a la espera de qué va a decir el presidente.

Sobre la vinculación de las personas migrantes con el proceso constituyente, en ese aspecto no hay garantías. Es difícil garantizar el voto, pero al menos deberíamos lograr que haya debate, ponerlos a pensar si necesario o posible que voten. Educar a través de franjas televisivas, folletería, con participación del Gobierno. Vincular a niños, migrantes, adultos mayores. El adulto mayor suele ser infantilizado o excluido. En el proceso de nuestras alcaldías constituyentes, se vincularon a los chicos desde los 16 años. Es interesante ese ejercicio desde el territorio, poder vincularlos y nutrirnos con otras perspectivas.

Es necesario que vinculen a los estudiantes y que nos vinculen a los migrantes como parte de la sociedad, pues también participamos activamente pagando impuestos, socializando e incluyendo a la comunidad. Si somos un factor de cambio para la población, también lo podemos ser para el país, sería muy interesante que nos vincularan. 


\section{Sobre los entrevistados}

David Órdenes es educador y planificador social, fundador y director ejecutivo de la Corporación La Caleta, integrante del Consejo de la Infancia como representante de la sociedad civil. Su correo electrónico es ordenesdavid@gmail.com.

HÉctor Morales es antropólogo, PhD en Antropología en la Universidad Libre de Berlín, Alemania, y profesor asistente de la Facultad de Ciencias Sociales de la Universidad de Chile. Ha hecho investigaciones e intervenciones socioculturales en etnodesarrollo, ciudadanía y génesis de movimientos sociales emergentes en comunidades aymaras, atacameñas, quechuas y mapuche-huilliche. Su correo electrónico es hmorales@uchile.cl.

JhoAny Acosta forma parte del colectivo Raíces de Resistencia, parte de la Coordinadora Nacional de Migrantes. Es colombiano residente en Chile desde hace ocho años. Su correo electrónico es wjacostapaez@gmail.com. 
El Anuario de Derechos Humanos es una publicación semestral de referencia y consulta en materia de derechos humanos y campos afines. Busca ser un espacio de discusión de los temas centrales en el ámbito nacional e internacional sobre derechos humanos. Es publicado desde 2005 por el Centro de Derechos Humanos de la Facultad de Derecho de la Universidad de Chile.

\author{
EDITORA \\ Claudia Iriarte Rivas \\ ciriarter@derecho.uchile.cl \\ SITIO WEB \\ anuariocdh.uchile.cl \\ CORREO ELECTRÓNICO \\ anuario-cdh@derecho.uchile.cl \\ LICENCIA DE ESTE ARTÍCULO \\ Creative Commons Atribución Compartir Igual 4.o Internacional
}

\author{
\% \\ La edición de textos, el diseño editorial \\ y la conversión a formatos electrónicos de este artículo \\ estuvieron a cargo de Tipográfica \\ (www.tipografica.io)
}

